\title{
Rehabilitation Engineering of Singapore Reefs to Cope with Urbanization and Climate Change Impacts
}

\author{
Loke Ming Chou \\ Tropical Marine Science Institute, National University of Singapore, Singapore 119227, Singapore
}

\begin{abstract}
Over $60 \%$ of Singapore's coral reefs have been lost to decades of coastal urbanization and heavy sedimentation has restricted coral development to the upper $5 \mathrm{~m}$ of the reef slope. High species diversity, predictable mass spawning events and vigorous growth of larval recruits indicate that active rehabilitation can help enhance reef resilience to urbanization and climate change impacts. Rehabilitation techniques selected should address high sedimentation, destabilized reef substrate and reef community structure change. Coral species dominance has shifted to favor those more tolerant of reduced light. Initiating rehabilitation with these dominant species can stabilize the reef substrate quickly. Coral nurseries with raised mesh-net platforms prevent sediment smothering and improve survival of coral fragments and juveniles. Juveniles have also naturally recruited and developed on seawalls constructed in non-reef areas. Innovative design and engineering of coastal defenses can facilitate coral growth as sea level rises. Floating reefs and seawalls that incorporate terraced tidal pools can encourage continued growth and development of coral communities. Two approaches considered appropriate to rehabilitating coral communities exposed to impacts of urbanization and climate change are: (1) increase of live coral cover and diversity of degraded reefs; (2) creation of reef communities in non-reef areas.
\end{abstract}

Key words: Coral reef, rehabilitation, urban, climate change impacts.

\section{Introduction}

Singapore's extensive coastal development over the last five decades has resulted in a $60 \%$ loss of coral reefs $[1,2]$. Impacts of this rapid urbanization on the marine environment include increased sedimentation, which reduced underwater visibility and sunlight penetration resulting in confinement of the healthy coral growth zone to the reef crest and the upper $5 \mathrm{~m}$ of the reef slope [3]. Despite exposure to continued anthropogenic pressure, the remaining reefs retain an ecological vigor in terms of growth, reproduction and recruitment $[4,5]$. Scleractinian coral species decline is not evident and modelling studies show the reefs to be self-seeding with the production of adequate larval supply $[6,7]$. New challenges are posed by climate change impacts. Elevated sea surface temperature caused two major coral bleaching events in 1998 and

Corresponding author: Loke Ming Chou, Ph.D., professor, research fields: coral reef ecology, reef restoration and coastal management.
2010 but the reefs have since recovered $[8,9]$. A number of reef restoration and rehabilitation projects have been implemented in the past and some are on-going. They all demonstrate the feasibility of this intervention under the challenging conditions of urbanization and climate change [10,11].

\section{The Case for Rehabilitation}

\subsection{Improved Management}

Singapore's coral reefs have not been under any form of legal protection in the past and the lack of an integrated coastal management framework resulted in the low priority accorded to their protection. The establishment of the Biodiversity Centre by National Parks Board in 1994 and the expansion of its mandate to cover the marine environment began to address these limitations [12]. Improved management became evident from the mid-1990s when development projects had to account for impacts to living resources including coral reefs. Impact assessments and 
mitigation measures became embedded in these projects, including coral relocation to mitigate reef loss. At the same time, the formation of the Inter-Ministerial Technical Committee on Coastal and Marine Environment in 2007 with representatives from all relevant agencies provided a framework that would support an integrated coastal management approach. A significant marine conservation milestone was reached in 2014 with the establishment of Singapore's first marine park (Sisters' Islands Marine Park), which ensured effective protection of the coral reefs and other habitats within its boundary.

\subsection{Biological Processes}

Most of Singapore's coral reefs fringe the southern offshore islands. Reefs along the mainland have all been eliminated, except for a small reef community at Labrador beach. There are also restricted reef communities associated with the northeast offshore islands. The change in environmental conditions caused by urbanization has depressed the abundance of many species but species elimination is not apparent. Of the 255 species of hard coral recorded from the reefs, only two are confirmed to be locally extinct $[3,6]$. Historical records depict a rich biodiversity and despite the varied and persistent impacts, new records of species not previously known to occur are still being made [13]. Singapore's reef biodiversity trend shows that while species elimination is less than expected, the distribution and abundance of many species have stayed depressed [2].

Coral community structure has changed to favour foliose growth forms with suitably large surface area that can receive as much of the reduced solar energy as possible. Branching Acropora corals, which dominate reefs of the region, are now uncommon in Singapore reefs because of past harvesting pressure and present environmental impacts. The intertidal reef flat supports species such as Favia, Favites, Goniastrea, Platygyra, and Oulastrea that can tolerate intermittent periods of exposure. The reef crest supports the best coral diversity where large colonies of Porites, Diploastrea and Symphyllia are present. Those that have a foliose or laminar growth form, such as Pectinia, Turbinaria and Pachyseris, dominate the lower reef slope as their large surface area enables them to optimise the available low light energy.

Despite urbanization impacts, essential biological processes remain intact. Mass spawning events where many coral species synchronously release eggs and sperm or fertilized egg bundles, occur consistently during the April full moon [5]. This is followed by a smaller event in September or October and timed to coincide with the inter-monsoon lull to improve larval survival. The pomacentrid fish species also spawn during the inter-monsoon periods [14].

Sea surface temperature elevation associated with the ENSO (El Niño Southern Oscillation) events in 1998 and 2010 affected Singapore's coral reefs at unprecedented levels. The 1998 warming caused more than $90 \%$ of all corals to bleach with a $20 \%$ mortality. The 2010 event caused another mass coral bleaching with a $10 \%$ mortality. However, differences in species mortality patterns were observed where species that were severely affected in the 1998 event appeared to be less so in 2010 [15]. In both cases, vigorous natural recruitment helped to hasten recovery.

Newly-created and modified habitats continue to support life. Species extinction is not high, as many are redistributed by the changing urban seascape. Ecosystem processes have not been completely compromised. Seasonal mass spawning of corals, recruitment and growth patterns of other marine species all indicate that ecological integrity is still maintained [4].

\subsection{Relevant Reef Rehabilitation Approaches}

Marine environment utilization remains intense and there is a need to examine approaches that not only minimize coral reef degradation but also enhance coral development in degraded reefs and non-reef 
areas. Active reef rehabilitation can help to reduce the rate of loss as well as reverse the trend. Research should be directed at addressing: (1) how restoration can assist effectively with the recovery of degraded reefs; (2) if "new" reefs can be created from transplanted corals.

Coral nurseries, whether in situ or ex situ, can perform as reserves to protect the diversity of reefs facing impending impact from coastal development, particularly that of sedimentation. Their establishment is useful in rehabilitation as they serve to protect and nurture coral fragments in a more secure situation until these reach a suitable size for transplantation where their survival chance is increased $[16,17]$. In high sediment conditions, in situ nurseries with taut mesh net platforms elevated above the reef bed are most relevant as sediment accumulation around the base of coral fragments is prevented.

Studies involving the rearing of "corals of opportunity" (i.e., naturally fragmented corals or coral juveniles that have recruited on loose rubble) and nubbins (very small fragments) have shown that appreciable survivorship and growth rate can be achieved in Singapore's sediment-impacted waters with the use of carefully sited in situ coral nurseries $[18,19]$. These studies also highlighted the feasibility of establishing coral nurseries to nurture species of coral fragments from reefs that are to be directly affected by coastal development in order to preserve scleractinian genotypes from these localities.

Rehabilitation success in heavily urbanized settings can be enhanced by observing coral species that have become dominant as they have adapted well to changed environmental parameters [3]. Rehabilitation can be initiated with the dominant species to stabilize the rehabilitation site within the shortest time and research on community structure dynamics is important. While the initial emphasis is on the adaptable species, the holistic approach necessitates the use of other species so that rehabilitated reefs retain sufficient species diversity that contribute to structural complexity.

\subsection{Rehabilitation for the Future}

Seawalls are a common engineering feature in urban coastal settings. Their primary function is to prevent erosion of reclaimed land and protect against storm surge. They are raised to perform an additional defensive role against sea level rise. Seawalls provide a hard substrate that is suitable for coral recruitment and growth and such natural recruitment has been observed [20]. A study showed that depth influenced the distribution of coral communities on the seawalls and only the chart datum zone supported coral growth. Active restoration enhanced the biodiversity of this zone of the seawall [21]. Seawalls line more than $60 \%$ of Singapore's coastline and offer a huge potential as alternative areas for the development of new coral communities [22]. The potential can be enhanced by increasing the surface complexity of seawalls [23].

Eco-engineering of seawalls can optimize their role further so that they not only provide passive defence against sea level rise, but also offer alternative sites for habitat development. Incorporating terraced cells that simulate tidal pools can increase the zone and area for coral community growth up to the high tide level as they are filled during high tide and retain water as the tide ebbs. These cells should be sufficiently large and deep to prevent overheating and evaporation of the contained water. Variation in size, height, volume and shape will increase the differences in environmental condition within and between them so that they become more conducive to harbouring and supporting a greater diversity of reef species, and help some to overcome temperature elevation.

Another approach is to have floating reefs where coral and other reef-associated species are placed on supporting structures attached to a floating platform, which overcomes the impact of sea level rise. The platforms can be towed to areas of stronger water flow or the supporting structures lowered to deeper depths when sea surface temperature elevates, so that the 
corals are less exposed to bleaching.

\section{Conclusions}

Active rehabilitation of coral reefs is necessary to mitigate coastal development impacts. Corals from reefs threatened by anthropogenic impacts can be collected and raised in nurseries to conserve genetic diversity as they are transplanted to other sites to enhance biodiversity. The conventional approach is to rehabilitate degraded reefs to improve health and resilience. A more relevant approach is to take into account anthropogenic and future climate change impacts and incorporate engineering innovations for the creation of new reefs.

\section{Acknowledgments}

The Maritime and Port Authority of Singapore is supporting an on-going research on reef rehabilitation through the project "Enhancing Singapore's Coral Reef Ecosystem in a Green Port" awarded to the Tropical Marine Science Institute of the National University of Singapore. An earlier and briefer version of this paper appears in the Proceedings of the Second International Conference on Disaster Management and Civil Engineering (2016), and is here expanded and updated [24].

\section{References}

[1] Hilton, M. J., and Manning, S. S. 1995. "Conversion of Coastal Habitats in Singapore: Indications of Unsustainable Development." Environmental Conservation 22: 307-22.

[2] Chou, L. M. 2006. "Marine Habitats in One of the World's Busiest Harbours." In The Environment in Pacific Harbours, edited by Wolanski, E. Dordrecht: Springer.

[3] Chou, L. M. 2010. "Marine Ecosystems." In Singapore Biodiversity: An Encyclopedia of the Natural Environment and Sustainable Development, edited by $\mathrm{Ng}$, P. K. L., Corlett, R. T., and Tan, H. T. W. Singapore: Editions Didier Miller.

[4] Chou, L. M., Toh, K. B., Tay, Y. C., and Phang, V. X. H. 2012. "Coral Reefs in Singapore: Past, Present and Future." In Proceedings of the 2012 Asian Conference on Sustainability, Energy and the Environment, 431-6.
[5] Guest, J. R., Baird, A. H., Goh, B. P. L., and Chou, L. M. 2002. "Multi-specific, Synchronous Coral Spawning in Singapore." Coral Reefs 21: 422-3.

[6] Huang, D. W., Tun, K. P. P., Chou, L. M., and Todd, P. A. 2009. "An Inventory of Zooxanthellate Scleractinian Corals in Singapore, Including 33 New Records." Raffles Bulletin of Zoology 22: 69-80.

[7] Tay, Y. C., Todd, P. A., Rosshaug, S., and Chou, L. M. 2012. "Simulating the Transport of Coral Larvae Among the Southern Islands of Singapore." Aquatic Biology 15: 283-97.

[8] Chou, L. M., and Tun, K. 2005. "Status of Coral Reefs in Southeast Asian Countries: Singapore." In Status of Coral Reefs in the East Asian Seas Region: 2004, edited by Japan Wildlife Research Center. Tokyo: Ministry of the Environment.

[9] Tun, K., Chou, L. M., Low, J., Yeemin, T., Phongsuwan, N., and Setiasih, N. et al. 2010. "A Regional Overview on the 2010 Coral Bleaching Event in Southeast Asia." In Status of Coral Reefs in East Asian Seas Region: 2010, edited by Japan Wildlife Research Center. Tokyo: Ministry of the Environment.

[10] Tan, H. T. W., Chou, L. M., Teo, D. C. J., and Ng, P. K. L. 2007. The Natural Heritage of Singapore. 2nd ed. Singapore: Prentice Hall.

[11] Ng, C. S. L., Toh, T. C., and Chou, L. M. 2016. "Coral Restoration in Singapore's Sediment-Challenged Sea." Regional Studies in Marine Science. http://dx.doi.org/10.1016/j.rsma.2016.05.005

[12] Chou, L. M. 2008. "Nature and Sustainability of the Marine Environment." In Spatial Planning for a Sustainable Singapore, edited by Wong, T. C., Yuen, B., and Goldblum, C. Dordrecht: Springer.

[13] Chou, L. M. 1994. "Coastal and Marine Habitats." In $A$ First Look at Biodiversity in Singapore, edited by Wee, Y. C. and Ng, P. K. L. Singapore: National Council on the Environment.

[14] Low, J. K., Leng, C. B., and Chou, L. M. 1997. "Pomacentrid Population Dynamics on Singapore Coral Reefs." Environmental Monitoring and Assessment 44: 53-66.

[15] Guest, J. R., Baird, A. H., Maynard, E. M., Muttaqin, E., Edwards, A. J., and Cambell, S. J., et al. 2012. "Contrasting Patterns of Coral Bleaching Susceptibility in 2010 Suggest an Adaptive Response to Thermal Stress." PLOS ONE 7: 1-8.

[16] Epstein, N., Bak, R. P. M., and Rinkevich, B. 2003. "Applying Forest Restoration Principles to Coral Reef Rehabilitation." Aquatic Conservation: Marine and Freshwater Ecosystems 13: 387-95.

[17] Rinkevich, B. 2005. "Conservation of Coral Reefs through Active Restoration Measures: Recent 
Approaches and Last Decade Progress." Environmental Science \& Technology 39: 4333-42.

[18] Chou, L. M., Yeemin, T., Abdul Rahim, B. G. Y., Vo, S. T., Alino, P., and Suharsono., et al. 2009. "Coral Reef Restoration in the South China Sea." Galaxea, Journal of Coral Reef Studies 11: 67-74.

[19] Bongiorni, L., Giovanelli, D., Rinkevich, B., Pusceddu, A., Chou, L. M., and Danavaro, R. 2011. "First Step in the Restoration of a Highly Degraded Coral Reef (Singapore) by In Situ Coral Intensive Farming." Aquaculture 322-323: 191-200.

[20] Ng, L. C. S., Chen, D. X., and Chou, L. M. 2012. "Hard Coral Assemblages on Seawalls in Singapore." In Contributions to Marine Science, edited by Tan, K. S. Singapore: Tropical Marine Science Institute.

[21] Ng, L. C. S., Lim, S. C., Ong, J. Y., Teo, S. L. M., Chou, L. M., Chua, K. E., and Tan, K. S., et al. 2015
"Enhancing the Biodiversity of Coastal Defence Structures: Transplantation of Nursery-Reared Reef Biota onto Intertidal Seawalls." Ecological Engineering 82: 480-6.

[22] Lai, S., Loke, L. H. L., Hilton, M. J., Bouma, T. J., and Todd, P. A. 2015. "The Effects of Urbanisation on Coastal Habitats and the Potential for Ecological Engineering: A Singapore Case Study." Ocean \& Coastal Management 103: 78-85.

[23] Loke, L. H. L., Ladle, R. J., Bouma, T. J., and Todd, P. A. 2015. "Creating Complex Habitats for Restoration and Reconciliation.” Ecological Engineering 77: 307-13.

[24] Chou, L. M. 2016. "Rehabilitation of Coral Reefs Exposed to Urbanization and Climate Change Impacts." In Proceedings of the 2016 2nd International Conference on Disaster Management and Civil Engineering, 133-6. 